\title{
A ORGANIZAÇÃo dA INSTRUÇÃO PÚBLICA NO ESTADO DO PARANÁ NO INÍCIO DA REPÚBLICA: O DECRETO n 31 DE 29 DE JANEIRO DE 1890
}

\author{
Cristiane Silva Melo ${ }^{1}$ \\ Maria Cristina Gomes Machado ${ }^{2}$
}

\section{Introdução}

O primeiro regulamento de organização da instrução pública do estado do Paraná, instituído no início da República, foi o Decreto $\mathrm{n}^{\mathrm{o}} 31$, de 29 de janeiro de $1890^{3}$ (PARANÁ, 1890a). O documento expressou determinações para o ensino primário, Instituto Paranaense e Escola Normal. Definiu medidas importantes para a sistematização e o estabelecimento do ensino elementar nas regiões do estado.

No estado do Paraná, a segunda metade do século XIX caracterizou-se por intensas transformações políticas, econômicas, culturais e sociais. Em 17 de novembro de 1889, o Paraná deixou de ser uma província e passou para a categoria de um dos estados membros dos Estados Unidos do Brasil, iniciando o período republicano (CAMARGO, 2006). A República instituiu-se no estado sem maiores resistências e incidentes por parte de monarquistas liberais e conservadores, de modo que mudanças foram almejadas pela expressão política, sem o interesse de conservação do regime de Império (BALHANA; MACHADO; WESTPHANEN, 1969, p. 186). Houve aumento populacional nas diversas regiões paranaenses, bem como o progresso das atividades econômicas, com destaque para a produção agrícola e a extração da erva-mate e o desenvolvimento da política imigratória ${ }^{4}$. A ideia de tornar o Paraná uma nação moderna era difundida por diversos setores nesse estado.

A educação, concebida como elemento indispensável ao progresso social, tornandose tema de debates, foi destacada como algo fundamental para a formação do cidadão, no processo de assimilação cultural por imigrantes e na preparação para o trabalho. O ideário da necessidade de educar as classes populares e dispor maior oferta de educação a toda a população em condições de recebê-la fortaleceu-se ao lado do entendimento de que problemas sociais poderiam ser resolvidos, em parte, pela educação. Dessa forma, a primeira década republicana no Paraná foi marcada pela criação de diversas leis, decretos e regulamentos, com o objetivo de difundir escolas primárias. Oliveira (1994, p. 46) ressalta que "O Paraná, na primeira República, contou com variada legislação de ensino, nada menos que nove regulamentos, isso sem considerar as leis isoladas, alterando dispositivos ou inovando com base em alguma determinação federal".

Ao Estado foi atribuída a função de custear o ensino público e ofertar condições para a difusão das primeiras letras para o povo. Schena (2002, p. 31-32) comenta que

[...] já nos primeiros anos da República as autoridades paranaenses enfatizavam a instrução do povo como sendo o padrão por onde se poderia medir o estágio de civilização de uma nação. A instrução representava a base estável da prosperidade pública.

A educação foi percebida como fator contribuinte ao desenvolvimento e à modernização social. Assim,

A escola teve um papel de relevância no projeto de modernidade republicana que buscou a construção da nacionalidade brasileira, o desenvolvimento econômico e social, a ordem e o progresso. [...] houve a 
necessidade de especialização do edifício escolar que, ao atender as novas necessidades pedagógicas e higienistas, estaria contribuindo para a educação, um dos fundamentos da modernidade. (CASTRO, 2009, p. 123 , grifos do autor).

O Decreto de número 31, que regulamentou a instrução pública do estado do Paraná, datado de 29 de janeiro de 1890, possui 61 artigos. Nestes, foram abordadas normas para a instituição e organização da instrução primária elementar e instrução normal secundária do Estado do Paraná. Em suas premissas gerais, previa a obrigatoriedade do ensino e a oferta do ensino da moral, a qual deveria ser destituída de qualquer relação com dogmas religiosos, bem como defendia a liberdade de ensino, tornando livre o exercício do magistério.

Dentre os assuntos focalizados, destaca-se essa liberdade no exercício do magistério nos diferentes graus do ensino, as disciplinas a serem ministradas no ensino primário, a seleção e carreira do professorado, a ação do governo para a oferta e o custeamento do ensino público, os requisitos para a matrícula nas escolas primárias e a definição dos métodos de ensino para a instrução primária elementar do estado.

O documento foi elaborado e assinado por comissão composta por Eusébio Silverio da Mota, David Pernetts, Generoso Marques dos Santos, João Pereira Lagos, Jose Joaquim Franco Valle e Justiniano de Mello e Silva. Encontrava-se, no cargo da Secretaria de Estado, Evaristo Ferreira da Veiga Gonzaga, e coube ao presidente do estado, José Marques Guimarães ${ }^{5}$, decretar o regulamento.

A seguir, aborda-se a organização do ensino, expressa no Regulamento da Instrução Pública do Estado do Paraná de 1890, com destaque às medidas definidas para a estruturação do ensino primário e da escola normal.

\section{O Regulamento da Instrução Pública do Estado do Paraná e a organização da Instrução Primária}

O Regulamento frisou que a organização do ensino primário estabelecer-se-ia em dois graus. $\mathrm{O}$ primeiro, de caráter elementar, tornaria obrigatório o ensino das matérias de instrução moral e cívica; de leitura e escrita; de noções gerais e práticas de gramática portuguesa; de elementos de aritmética, com o sistema métrico; de desenho, com aplicação à indústria e às artes; e de prendas domésticas, nas escolas destinadas às meninas. $\mathrm{O}$ segundo, de caráter complementar, além do ensino das disciplinas mencionadas de maneira mais aprofundada, abordar-se-iam as matérias de Aritmética aplicada; os elementos do cálculo algébrico e da geometria; as regras da contabilidade usual e a escrituração mercantil; as noções de ciências físicas e naturais com aplicação à agricultura, às artes e à indústria; o desenho geométrico e de ornamento; e a geografia industrial e comercial.

O Decreto expressava a importância do ensino da moral. Esta foi enumerada como a primeira das matérias, cujo conteúdo perpassaria o ensino das demais disciplinas. Desse modo, tal matéria seria destinada a "[...] completar, consolidar e enobrecer todos os outros ensinos da escola." (PARANÁ, 1890a, p.42). Era tarefa do professor ensinar a moral, instigar a aprendizagem de noções essenciais referentes à moralidade humana, necessárias à formação de homens civilizados. A ênfase do ensino da moral não estava na instrução de dogmas religiosos, mas no desenvolvimento moral dos alunos, de maneira a aperfeiçoar o caráter para a socialização. Dessa maneira, tornava-se necessário assimilar conjuntos de regras de condutas e hábitos considerados importantes para a formação do caráter dos homens, uma vez que os princípios elementares sobre o bem e o mal já eram do 
conhecimento das crianças ao entrarem na escola. Esse posicionamento estava consoante com o novo discurso republicano, que promulgou a separação entre o Estado e a religião.

O Regulamento previa, sob pena de multas, o custeamento e a oferta do ensino elementar de instrução primária pelos fazendeiros, pelas fábricas ou pelos estabelecimentos industriais que empregassem mais de quinze crianças de sete a quatorze anos de idade em localidades onde não houvesse estabelecimentos de ensino numa distância de três quilômetros.

O Decreto presumia a construção pelo estado de casas escolares e o provimento de móveis, equipamentos e materiais didáticos para equipar as instituições de ensino. Cabia às câmaras municipais fornecer aos alunos pobres materiais escolares, tais como: penas e tinta, papel e livros ou compêndios.

Em caso de impossibilidade da criação de duas escolas, uma para meninos e outra para meninas, o decreto previa a instituição de uma cadeira de ensino promíscuo, isto é, um ensino oferecido a ambos, regido por um preceptor, permitindo, em caráter excepcional, a coeducação dos sexos. Nesse caso, os alunos seriam segregados: meninos e meninas seriam direcionados a ocupar bancos escolares separados nas instituições, reunindo-se apenas em ocasiões de exercícios e lições de classe, presididos pelo preceptor.

As matrículas dos alunos nas escolas primárias seriam efetivadas mediante a verificação do preceptor, que observaria se os alunos eram ou não vacinados. Caso fosse identificada a irregularidade quanto à não vacinação, ele deveria comunicar ao inspetor ou aos delegados de higiene, que tomariam as medidas cabíveis.

O Regulamento previa a criação de um Museu pedagógico e de uma biblioteca central do ensino primário, em anexo à Escola Normal. Ambos deveriam contemplar diversas coleções de material escolar, relatórios de professores e agentes de ensino, dados estatísticos sobre a instrução, livros didáticos nacionais e estrangeiros, entre outros itens.

O documento instituía, como abordagem de ensino em aulas de instrução primária elementar, o modo misto ou simultâneo mútuo, com destaque ao método de ensino intuitivo. Previa a organização de museus escolares com conteúdos, como plantas e minerais da região, que instigassem à curiosidade e à investigação dos alunos em contribuição à assimilação de conhecimentos provenientes do conhecimento concreto e direto das coisas ou dos objetos.

O modo misto ou simultâneo mútuo de ensino caracterizava-se pela organização e oferta de uma educação direcionada, simultaneamente, a todos os alunos em sala de aula, buscando aliar as vantagens do método individual às do método mútuo. Sobre as especificidades dos métodos, individual e misto, recorre-se à Oliveira (1994, p. 203), que define:

As aulas pelo método individual eram aquelas ministradas, visando atender cada aluno conforme seu adiantamento, tendo em vista que, numa mesma sala, freqüentavam alunos de diferentes níveis de aprendizagem, sob a orientação de um só professor. Pelo misto, eram as aulas ministradas para todos os alunos indistintamente e, ao mesmo tempo, com explicações individuais para os que não tivessem compreendido o assunto.

O método simultâneo obteve presença expressiva no campo educacional brasileiro no século XIX, tornando-se o mais indicado a ser aderido pelos professores para o ensino.

[...] a discussão sobre o método de ensino, entendido muito mais como forma de "organização da classe" como "forma de ensinar", vai se 
processar, no Brasil, no decorrer dos anos 40 a meados dos anos 70 do século XIX. Assim, já no final dos anos 30, o método mútuo dará lugar, em várias províncias e em vários textos legais, aos chamados "métodos mistos", os quais buscavam ora aliar as vantagens do método individual às do método mútuo, ora aliar os aspectos positivos deste último às inovações propostas pelos defensores do "método simultâneo".

Com o decorrer do tempo, vai-se estabelecendo que o método simultâneo era o que melhor atendia às especificidades da instrução escolar, permitindo a organização de classes mais homogêneas, a ação do professor sobre vários alunos simultaneamente, a otimização do tempo escolar, a organização dos conteúdos em diversos níveis, dentre outros elementos. (FARIA FILHO, 2000, p. 142).

Nas décadas finais do século XIX, é propagado no país o método intuitivo, concebido como algo inovador, moderno e útil para um ensino eficaz, sendo o mais indicado a ser utilizado na instrução elementar. Em 1886, foi publicada no Rio de Janeiro a obra Primeiras Lições de Coisas, versão de Rui Barbosa de Primary Object Lesson, de Alison Calkins (1886). Esse material sobre o método intuitivo consistiu em um manual de ensino destinado à utilidade de professores e pais na educação de crianças. Nos anos finais do Império, a obra foi adotada pelo Governo para o uso dos educadores nas escolas primárias.

O método intuitivo considerava o instigar a aprendizagem por meio dos sentidos, que possibilitavam ao aluno a produção de ideias e conhecimentos. Os materiais concretos, selecionados a partir da realidade e da vivência do aluno, permitiam sua compreensão e a formulação de conceitos, sendo o processo de observação e experiências reais importantes para a aprendizagem. Acreditava-se que era do sentido que provinha o conhecimento do mundo material, devendo o mesmo ser estimulado para o desenvolvimento da curiosidade, percepção, imaginação e do conhecimento. Sobre os princípios das Lições de Coisas e o método intuitivo, Rui Barbosa (1886, p. 1-3, grifos do autor) comenta:

O Primeiro passo preparatório para a educação de crianças convém que seja estudar a natureza do espírito e sua condição na puerícia, seus modos naturais de desenvolvimento e os processos melhor adaptados a disciplinar-lhe acertadamente as faculdades. Obtidas essas noções, fácil empenho será o afeiçoar de acordo com elas o ensino. Como intróito a essa diligência preliminar, indicaremos alguns fatos, que lhe sirvam de base.

1. É pelos sentidos que nos advém o conhecimento do mundo material. Os primeiros objetos onde se exercem as nossas faculdades, são as nossas faculdades, são as coisas e os fenômenos do mundo exterior.

2. A percepção é a primeira fase da inteligência; e, pois, de ver esta que a educação há de começar pela cultura das faculdades perceptivas. Consiste principalmente essa cultura em proporcionar ocasiões e estímulos ao desenvolvimento delas, e fixar as percepções nos espíritos pelos meios representativos, que a palavra nos subministra.

3. A existência de uma noção no espírito nasce da percepção das semelhanças e diferenças entre os objetos. Os conhecimentos avultam em proporção do talento crescente de discernir as afinidades e dissemelhanças, assim como da capacidade progressiva de associar e classificar as coisas, experiências e fatos que uns com os outros se aparentam. 
4. Todas as faculdades medram, e robustecem a poder de exercício adequado; correndo o risco de se debilitarem, se as sobrecarregamos, ou se as aplicamos a matérias que não estejam naturalmente ao seu alcance.

5. Algumas das energias mentais são tão ativas e quase tão vigorosas no menino, quanto no homem: tais a sensação, a percepção, a observação, a comparação, a simples retentiva e a imaginação. Outras não chegam ao seu desenvolvimento cabal, antes que a criança toque o período de madureza. Entre estas a razão, a memória filosófica e a generalização.

6. O mais natural e saudável incentivo para obter, entre crianças, a atenção e a aquisição de conhecimentos, é associar a recreação ao ensino. A curiosidade, ou desejo de saber, e o amor do maravilhoso são grandes princípios atuantes na infância, cuja satisfação traz sempre emoções deleitosas. Possuem as crianças uma nativa avidez de ciência e atividade. Um dos seus prazeres está no acertar. Outro poderoso agente de instrução vem a ser a confiança no próprio esforço.

7. É do bom ensino o inspirar contentamento 'a infância'; e, onde isso não se verifica, algum vício há, seja no modo de expor, seja na própria natureza do assunto, que se escolheu para objeto da lição.

8. Os hábitos de atenção firme são permanentes mananciais de educação intelectual. Ora, os hábitos adquirem-se pela reiteração do mesmo ato. Mas o grande segredo, para fixar a atenção das crianças, está em aguçar-lhes a curiosidade, e satisfazer-lhes o amor de atividade, em temperar o ensino com associações que o amenizem, e fugir de sobrecarregar-lhes jamais as faculdades, tendo-as por demasiado tempo concentradas no mesmo alvo.

9. O processo natural de ensinar parte do simples para o complexo; do que se sabe, para o que se ignora; dos fatos, para as causas; das coisas, para os nomes; das idéias, para as palavras; dos princípios, para as regras.

A adoção do método intuitivo ou lições de coisas previa um ambiente escolar estimulante à aprendizagem do aluno, com a existência de museus pedagógicos e laboratórios para estudo. O método foi visto como algo importante para mudanças efetivas na prática docente, em contraposição a um ensino baseado em métodos repetitivos, que geravam, exclusivamente, a habilidade de memorização pelo aluno. O ensino deveria considerar o aprendiz como sujeito ativo no processo de assimilação de conhecimentos, visando à sua compreensão do simples para o complexo, do concreto para o abstrato, contribuindo para sua formação social.

Quando de seu surgimento e proliferação [lições de coisas], são creditadas a esse novo método de ensino muitas esperanças. Acredita-se que sua prática nas escolas pode tornar os alunos mais autônomos, sem ficarem presos à memorização de textos, pode contribuir para o desenvolvimento da capacidade de julgamento, pode levá-los a um domínio maior da linguagem, contribuindo assim para o desenvolvimento econômico e social, função explicitamente atribuída à escola primária. Investindo contra o caráter abstrato e pouco utilitário da educação corrente, o método de ensino intuitivo é proposto associado a novos materiais didáticos (caixas para ensino das cores e das formas, gravuras, coleções, objetos variados de madeira, aros, linhas, papéis etc.), a museus pedagógicos, a novas atividades para serem desenvolvidas nas salas de aula, difundindo-se e popularizando-se por meio de exposições 
universais, organizadas para a divulgação de práticas pedagógicas renovadas, de novos materiais e suas aplicações (WARDE, 2002; KUHLMANN JR., 2001). (VALDEMARIN, 2006, p. 173-174, grifo do autor)

Após a definição do método a ser adotado, o Regulamento da Instrução Pública do Estado do Paraná sinalizava que a administração e fiscalização do ensino eram incumbência do governo do Estado; do diretor geral da instrução, escolhido dentre os professores do Instituto Paranaense e da Escola Normal e nomeado pelo governo; da Escola Normal; dos inspetores literários e dos delegados especiais, nomeados eventualmente pelo governo para exercerem a inspeção no território do estado. O governo poderia comissionar o professor de pedagogia da Escola Normal, ou os delegados de ensino, para visitar e fiscalizar as escolas e indicar, para os professores, os métodos e programas convenientes ao ensino.

A intervenção do estado em assuntos relacionados à educação era preeminente; sua ação envolvia, em especial, fundar e equipar instituições de ensino públicas, com vistas à maior propagação do ensino a toda a população. No Paraná, na segunda metade do século XIX, nota-se um aumento no número de escolas em diversas regiões. Segundo Oliveira (1994, p. 44),

No final do Período provincial, a rede escolar pública e particular de ensino primário no Paraná contou com 199 escolas criadas, distribuídas por 130 localidades, a saber:

a) 180 escolas da rede pública (do governo), sendo:

- 43 vagas (sem professores);

- 123 públicas;

- 1 subvencionada;

- 10 municipais;

- 3 regimentais;

b) 19 escolas particulares.

Além das escolas primárias, a de ensino secundário oficial, funcionando em Curitiba, foi o Instituto Paranaense. Dos cursos profissionalizantes havia a Escola Normal, três cursos Mercantil e a Escola de Artes e Indústria.

$[\ldots]$

Nos trinta e seis anos de Província, o Governo conseguiu expandir a rede escolar por mais 112 localidades sobre 18 existentes em 1853, totalizando 214 estabelecimentos entre escolas primárias, secundárias e profissionalizantes, públicas e particulares.

A educação era compreendida como algo importante e necessário ao progresso social. A fundação de escolas, pelo estado, também foi visada no decorrer do século XX. Propagar a educação era meta de um projeto civilizatório e de modernização da sociedade em prol de seu desenvolvimento. No Paraná, Curitiba foi a cidade que mais contemplou a construção de prédios escolares e, consequentemente, a expansão de maiores condições de acesso ao ensino.

No Paraná, durante a Primeira República, 36 edifícios destinados à instrução primária foram construídos. [...] grande número dessas escolas [foram fundadas] na capital do Estado, $22 \%$ do total. Curitiba ganhou, no período, oito edifícios projetados e construídos como escolas primárias, enquanto as demais cidades, quando contempladas, receberam apenas um. [...] 
São curitibanos o primeiro e o último grupo escolar da Primeira República, o Dr. Xavier da Silva e o D. Pedro II. Eles podem ser considerados marcos referenciais da arquitetura escolar e do processo de constituição e disseminação de escolas públicas no Paraná. O primeiro iniciou o processo, dentro da concepção de graduação do ensino; o segundo materializou a sua consolidação, já amadurecida pelo percurso de 25 anos. (CASTRO, 2009, p. 142)

Apesar de haver, entre o final do século XIX e o início do século XX, um maior investimento na fundação de instituições de ensino, bem como maior expressão do tema organização do ensino na legislação do estado, notava-se que muito ainda era necessário fazer para a efetivação de um ensino de qualidade no âmbito do campo educacional. Necessidades como maiores recursos para as escolas, maior valorização da formação e carreira do profissional docente, políticas para matrícula e permanência de alunos em instituições de ensino faziam-se presentes, sendo verificados problemas, tais como: recursos precários, falta de professores, baixa frequência e evasão de alunos nas escolas.

Com base na análise das fontes primárias sobre a instrução pública primária de 1854 a 1889 , considera-se que não houve uma estruturação real do ensino nesse período. $\mathrm{O}$ que houve foi uma preocupação em legislar sobre o assunto, resultando em um excesso de leis e regulamentos e a abertura desordenada de escolas pelo governo provincial, atendendo a interesses locais, na sua maioria políticos.

Pode-se dizer que o governo da província expandiu a rede de instrução primária pública ao abrir escolas em diversas localidades, mas não que esse tenha sido um movimento em prol da instrução, pois em nenhum momento o governo conseguiu prover as escolas dos elementos essenciais para seu funcionamento, em razão da falta de recursos. Faltava tudo: professores, local apropriado, bancos, mesas, cartilhas, livros, papel, tinta etc., principalmente para os dirigentes, que, pelo regulamento de 8 de abril de 1857, deveriam receber o material do governo da província. Essas questões, juntamente com as reclamações dos professores quanto aos baixos vencimentos, baixo índice de matrículas e pouca frequiência dos alunos, acabaram por caracterizar o período estudado. (BLANCK MIGUEL, 2006, p. 205-206)

É expressiva a quantidade de relatórios de Ministros do Império e Presidentes de Províncias que relataram problemas na organização e oferta da educação ao longo do período imperial. Em relação à educação em âmbito nacional, nesse período, notam-se inúmeras críticas quanto à insuficiência quantitativa e qualitativa de prédios escolares, a falta de capacitação de docentes e a ineficácia de métodos de ensino. A República viria a encontrar certa inorganização no sistema de ensino, de modo a deparar com o seguinte quadro: um ensino primário ministrado, em grande parte, por professores leigos; poucas escolas normais destinadas à formação para o magistério; um ensino secundário caracterizado pela predominância de cursos avulsos e aulas régias, sem organização hierárquica de matérias e séries; e um ensino superior reduzido a poucas faculdades isoladas, destinadas, em especial, à preparação de profissionais liberais.

A República não teve de enfrentar uma simples deficiência quantitativa, mas - o que era mais grave e mais difícil de ser modificado - uma deficiência qualitativa. Em todos os níveis da nossa organização escolar 
ministrava-se um ensino pobre de conteúdo, desligado da vida, sem qualquer preocupação filosófica ou científica e que somente conseguiu fazer alguns indivíduos alfabetizados, de poucos conhecedores de Latim e Grego, e de pouquíssimos "doutores”. (HOLANDA, 1985, p. 382-383)

No Paraná, maiores investimentos no desenvolvimento do ensino são notados nas décadas iniciais da República, sendo que a expansão da rede escolar foi determinante para o direcionamento e aumento de verbas à instrução pública. Segundo Oliveira (2006, p. 395), "a partir de 1896, a economia paranaense começou a ganhar impulso, refletindo-se na receita estadual e possibilitando maiores investimentos em obras públicas, força pública e instrução pública. As aplicações em obras viárias absorveram 23,8\%, enquanto a instrução ficou com 12,1\%.". Entre o período de 1929 e 1930, a verba destinada à instrução pública foi a mais elevada, com grande parte da receita destinada aos vencimentos dos professores.

Ressalta-se a preocupação, desde as décadas de 1880 e 1890, com a criação de cursos superiores, em especial, de uma universidade no Paraná. No ano de 1891, decretase, no jornal Diário do Comércio, dirigido por Leôncio Correia, em matéria datada de 27 de junho desse ano, a primeira notícia sobre a Universidade de Rocha Pombo. Em 19 de dezembro de 1912, é oficializada, pela Lei Estadual no 1.284, a criação da Universidade do Paraná, da qual faziam parte as Faculdades de Direito, Engenharia, Odontologia, Farmácia e Comércio, cuja primeira diretoria foi composta pelos seguintes nomes: Victor Ferreira do Amaral e Silva, como Diretor; Euclides Beviláqua, como Vice-diretor; Nilo Cairo, como Secretário; Daltro Filho, como Subsecretário; Flávio Luz, como Tesoureiro; e Hugo Gutierrez de Simas, como Bibliotecário. O decreto federal de reconhecimento oficial da Universidade do Paraná foi o de $\mathrm{n}^{\circ}$ 9.323, de 1946, Victor Ferreira do Amaral foi mantido no cargo de Reitor, o que simbolizou a continuidade da Universidade, desde 1912. (PROSSER, 2004).

No início da República, não havia dúvida, para os legisladores, em relação à necessidade de expansão do ensino, mormente do ensino primário público. Contudo, esbarrava-se na falta de verbas, bem como de professores qualificados que dominassem os novos métodos pedagógicos. Dado o importante papel do professor, sua formação e condições de trabalho, isso foi tratado com afã, em nível de discurso, pelos legisladores republicanos, que dedicaram uma boa parte do regulamento a essas questões.

\section{O Regulamento da Instrução Pública do Estado do Paraná, a Escola Normal e as condições dos professores do ensino primário}

O regulamento definiu que a instrução normal ou secundária seria oferecida gratuitamente por institutos criados na capital com as denominações de Instituto Paranaense e Escola Normal. O curso teria a duração de dois anos e compreenderia o ensino de desenho, ofertado pela Escola de Artes de Indústrias da região.

O Decreto previa a liberdade de ensino, destacando o livre exercício do magistério nos graus do ensino primário, assim como a escolha de métodos, programas e compêndios em escolas privadas. Definiu a necessidade de abertura de estabelecimentos de ensino privado, o que deveria ser comunicado ao diretor geral da instrução pública do estado. Era preciso que organizadores de escolas privadas fornecessem informações sobre $o$ funcionamento da instituição ao referido diretor ou aos inspetores literários quando necessário.

O regulamento definiu normatização quanto à seleção e à carreira dos docentes de instituição de ensino público. O Decreto definia ainda a necessidade de os candidatos ao 
magistério público provarem, perante o diretor da instrução, a maioridade de 18 anos, moralidade (mediante declaração e atestado pelas autoridades civis) e capacidade profissional.

Os exames para admissão de professores, segundo o Decreto, realizar-se-iam em duas épocas do ano: fevereiro e julho. Cabia à comissão examinadora organizar a lista dos candidatos aprovados, da qual seriam convocados professores para reger as cadeiras de ensino.

O Decreto previa que a Escola Normal instituiria medalhas e diplomas de honra aos preceptores que se distinguissem no magistério, sendo o nome dos homenageados incluído em atas de sessões a serem publicadas, com destaque, pelos serviços meritórios prestados à instrução pública. Definia a possibilidade de o governo do estado conceder licença aos professores que almejassem frequentar o curso normal e apresentassem substituto idôneo, aprovado pelo diretor da instrução.

A Escola Normal no estado do Paraná foi criada na década de 1870. A lei $\mathrm{n}^{\circ} 238$, de 19 de abril de 1870, instituiu na capital uma Escola Normal para o ensino das pessoas que quisessem exercer a docência na instrução elementar. Em seu artigo segundo, a lei definia que o curso normal na escola compreenderia as seguintes matérias: Caligrafia, Gramática filosófica, Doutrina da religião cristã, Aritmética, Sistema métrico, Desenho linear, Noções de geografia, especialmente do Brasil, e Noções de história do Brasil. Em seu artigo terceiro, estabelecia ser o curso normal de dois anos, nos quais se distribuiria convenientemente o estudo das matérias referidas. (PARANÁ, 1870).

O currículo da Escola Normal contemplava apenas disciplinas essenciais. A falta de profissionais qualificados para lecionar na escola levou à hipótese de contratação de professores de outras províncias, de maneira que a estruturação dessa escola sofreu críticas pelas despesas que sua manutenção geraria à província. Segundo Oliveira (1986, p. 59), “a criação dessa escola, embora houvesse ficado somente no plano legal, influiu na situação funcional do professorado, fazendo cessar o provimento vitalício e estabelecendo a ocupação de vagas no magistério por interinos que seriam substituídos, tão logo houvesse professor normalista." Assim, acentuou-se o reconhecimento acerca da necessidade de estabelecimento específico para a preparação de professores à carreira de magistério, porém notava-se falta de investimento por parte do Estado na fundação e manutenção de Escolas Normais nas diversas localidades do estado.

A segunda metade do século XIX foi marcada por poucos investimentos na educação pública, pela falta de iniciativas das províncias com a finalidade de suprir a falta de escolas de preparação de professores e com diretrizes educacionais para atender às necessidades do período. Diversas leis educacionais foram criadas para atender às províncias, como demonstração de preocupação com as necessidades locais de instrução e para mostrar uma efetiva atuação do Estado. Porém, foram leis que não se concretizaram na prática. (NASCIMENTO, 2008, p. 79, grifos nossos).

A quantidade de instituições próprias para o ensino do magistério no período imperial foi reduzida em todo o país. Em 1867, têm-se o registro, por Liberato Barroso, de apenas 4 (quatro) estabelecimentos dessa modalidade de ensino no país, e, em 1883, o apontamento de cerca de 22 (vinte e duas) instituições (TANURI, 2000). A maioria das províncias possuía poucas escolas normais destinadas à formação do professorado primário, em diversas localidades havia poucas escolas normais e muitas das escolas fundadas possuíam duração efêmera. 
No final do Império, a maioria das províncias não tinha mais do que uma escola normal pública, ou quando muito duas, uma para o sexo feminino e uma para o masculino, organizadas com dois a quatro anos de estudos, geralmente três. Em algumas províncias, como é o caso de Goiás (Canezin \& Loureiro, 1994, p. 33), apenas a Cadeira de Pedagogia, junto às disciplinas do liceu, fazia às vezes de curso de preparação de professores. Via de regra, as escolas normais não alcançavam ainda o nível do curso secundário, sendo inferiores a este quer no conteúdo, quer na duração dos estudos. Já então com um currículo mais amplo do que o inicial, composto sobretudo pelas matérias do ensino primário, elas se assemelhavam às escolas primárias superiores, constantes da legislação de muitas províncias. A formação pedagógica era reduzida, limitando-se a uma ou duas disciplinas: pedagogia (e/ou metodologia), acrescida às vezes de legislação e administração educacional. Mencione-se, a título de exemplo, o currículo da Escola Normal de São Paulo, fixado pelo Regulamento de 3/1/1887: $1^{\circ}$ ano: gramática e língua nacional, aritmética, gramática e língua francesa, doutrina cristã; $2^{\circ}$ ano: gramática e língua nacional, geometria física, gramática e língua francesa; $3^{\circ}$ ano: geografia e história, pedagogia e metodologia, química (art. $3^{\circ}$ ). (TANURI, 2000, p. 67)

O Decreto $\mathrm{n}^{\mathrm{o}} 31$, de 29 de janeiro de 1890, ao apresentar a normatização para a escola normal, expressa, por um lado, a importância que, aos poucos, foi sendo atribuída à necessidade de preparação do professorado para o ensino nas décadas finais do império. A organização da Escola Normal, de certo modo, influía no estabelecimento do ensino primário, uma vez que a instituição, no estado, representava a possibilidade de formação de professores para as cadeiras de magistério primário. Isso ainda se tornava possível pela função atribuída à referida instituição de assegurar a supervisão e organização da instrução elementar.

\section{Considerações finais}

O Regulamento da Instrução Pública do Estado do Paraná de 1890 norteou a organização do ensino em época de intensa definição de organização política e social no estado. Almejava-se uma educação mais acessível à população paranaense, com destaque para a possibilidade de o ensino primário atender a um número maior de pessoas, tendo em vista que o aumento populacional encontrava-se em expansão, devido às condições de urbanização e imigração.

A instrução pública foi considerada, desde os anos iniciais do Império, como algo importante, devendo, portanto, ser expandida, como expressa a Constituição Imperial, de 11 de dezembro de 1823. Esta determinou a criação de escolas de primeiras letras em todas as cidades, vilas e lugarejos sob a garantia de a instrução primária ser gratuita a todos os cidadãos; aliado a isso, o Decreto de 15 de outubro de 1827 estabelecia a primeira lei sobre a educação primária (HOLANDA, 1985). Porém, não houve no país, no decorrer do período, uma oferta significativa de escolas para as classes populares.

Assim, urgia a demanda por escolas, e a sociedade se mobilizava para promover mudanças, com a organização de novas relações de trabalho, mediante a abolição da escravidão e o advento de imigrantes. Em meio a esse cenário, a educação - posta como necessária à unidade nacional - foi considerada indispensável à instrução do povo. No final do século XIX, é fortalecida a preocupação com a expansão do número de escolas e, 
fundamentalmente, com o conteúdo a ser ensinado por elas, evidenciando-se a valorização dos conteúdos que garantissem a formação moral do cidadão.

Nesse contexto, a organização do ensino foi vista como necessidade de primeira ordem, com destaque para a importância de sua ampliação e oferta. Os temas educação e ensino primário foram enfatizados nas décadas iniciais da República, sendo visados em meio às discussões sobre a Primeira Constituição Republicana do Brasil, instituída em 1891. A Constituição de 1891, dentre diversas medidas, determinou a responsabilidade do Governo Central pelo ensino secundário e superior no país e pelo ensino primário no Distrito Federal, cabendo aos estados federados a responsabilidade pela criação e manutenção da escola primária.

No Paraná, políticos e governadores buscaram disseminar as escolas com base na legislação republicana. Inclusive, destaca-se que a instrução pública recebeu atenção de deputados constituintes em meio aos debates sobre a Constituição Paranaense de 7 de abril de 1892, que vigorou em conjunto com o Ato Adicional de 14 de outubro de 1893 até 1927 (MARTINS, 1995). A Primeira República ou República Velha - de 1889 a 1930 - atribuiu maior valorização ao desenvolvimento do ensino, sendo expressiva a quantidade de investimentos que o estado destinou à organização do ensino. Entretanto, esses investimentos, embora vultosos, não foram suficientes.

Com o advento da República, tornou-se urgente regulamentar todas as instituições, com base nos fundamentos teóricos e políticos republicanos. Cada estado federado criou, com urgência, leis para regulamentar internamente os serviços públicos. Nesse pacote, o Regulamento analisado foi tornado público em pouco mais de dois meses da queda da Monarquia.

As bases propostas prometiam alçar o Paraná à modernidade. O novo regulamento buscou tratar das questões centrais para a propagação do ensino. Algumas questões polêmicas, como a gratuidade, a obrigatoriedade, a liberdade de ensino e a laicidade, foram promulgadas e atendiam às expectativas de difusão da escola primária - escola para ler, escrever e contar enquanto espaço de formação de cidadania. Contudo, o ideário contrastava com a realidade, esbarrando-se na falta de recursos públicos para a efetivação do supracitado regulamento. Desse modo, registra-se a curta vigência dessa regulamentação. O Decreto $n^{\circ} 64$ de 11 de abril (PARANÁ, 1890b), em menos de três meses, revogou o Regulamento de Ensino - Decreto $n^{\circ} 31$, com a justificativa de que este não satisfazia às necessidades do ensino público e excederia as verbas consignadas para esse serviço. Com esse decreto, adiava-se a resolução dos problemas educacionais. Teoria e prática distanciavam-se nos primórdios da República. Adiavam-se os investimentos necessários à propagação da educação pública para os anos seguintes e, assim, sucessivamente.

\section{REFERÊNCIAS}

BALHANA, Altiva Pilatti; MACHADO, Brasil Pinheiro; WESTPHALEN, Cecília Maria. História do Paraná. Curitiba: Grafipar, 1969.

BARBOSA, Rui. Lições de Coisas. Rio de Janeiro: Imprensa Nacional, 1886.

BLANCK MIGUEL, Maria Elisabeth. A história da escola pública no Paraná: entre as intenções legais e as necessidades reais. In: SHELBAUER, Analete Regina; LOMBARDI, José Claudinei; MACHADO, Maria Cristina Gomes (Orgs.). Educação em debate: perspectivas, abordagens e historiografia. Campinas: Autores Associados, 2006. p. 187209. 
CAMARGO, João Borba de. História do Paraná: a República - 1889-2002. Maringá: Maranata, 2006.

CASTRO, Elizabeth Amorin de. A arquitetura dos grupos escolares do Paraná na Primeira República. Revista Brasileira de Estudos Pedagógicos. Brasília: INEP, v. 90, p. 122-148, jan./abr. 2009.

FARIA FILHO, Luciano Mendes de. A Instrução elementar no século XIX. In: LOPES, Eliane Marta Teixeira; FARIA FILHO, Luciano Mendes de; VEIGA, Cynthia Greive. 500 anos de educação no Brasil. Belo Horizonte: Autêntica, 2000. p. 135-150.

HOLANDA, Sérgio Buarque. História geral da civilização brasileira. São Paulo: Difel, 1985.

MAGAlHÃES, Marion Brepohl de. Paraná: Política e Governo. Curitiba: SEED, 2001.

MARTINS, Romário. História do Paraná. Curitiba: Travessa dos Editores, 1995.

NASCIMENTO, Maria Isabel Moura. A primeira escola de professores dos Campos Gerais - Pr. Ponta Grossa: Editora UEPG, 2008.

OLIVEIRA, Maria Cecília Marins de. Políticas e investimentos do Governo do Paraná na rede pública de ensino (1889-1930). Eccos, São Paulo, v. 08, n. 2, p. 385-405, jan./jun. 2006.

O ensino primário na província do Paraná (1853-1889). Curitiba: Secretaria de Estado da Cultura e do Esporte, 1986.

Ensino primário e sociedade no Paraná durante a Primeira República. 1994.

310 f. Tese (Doutorado em Educação) - Faculdade de Educação, Universidade de São Paulo, São Paulo, 1994.

PARANÁ. Lei no 238 de 19 de abril de 1870 (Atos Oficiais do Paraná - Legislação Provincial, Paraná, 1870). In: BLANCK MIGUEL, Maria Elisabeth (Org.). Coletânea da Documentação Educacional Paranaense no período de 1854 a 1889. Campinas, SP: Autores Associados; SBHE, 2000. p. 120 - 121.

PARANÁ. Regulamento da instrução pública do Estado do Paraná (Decreto no 31 de 29 de janeiro de 1890). Coleção Leis, Decretos e Regulamentos do Estado do Paraná. Curitiba: Arquivo Público do Paraná, 1890a. p. 39 - 50.

PARANÁ. Decreto no 64 de 11 de abril de 1890. Coleção Leis, Decretos e Regulamentos do Estado do Paraná. Curitiba: Arquivo Público do Paraná, 1890b.

PROSSER, Elisabeth Seraphim. Cem anos de sociedade, arte e educação em Curitiba: 1853-1953. Curitiba: Imprensa oficial, 2004.

SCHENA, Denilson Roberto. O lugar da escola primária como portadora de um projeto de nação: o caso do Paraná (1890-1922). 2002. Dissertação (Mestrado em Educação) - Programa de Pós-Graduação em Educação, Universidade Federal do Paraná, Curitiba, 2002.

TANURI, Leonor Maria. História da Formação de professores. Revista Brasileira de Educação. ANPED, n. 14, p. 61-88, mai.-ago. 2000.

VALDEMARIN, Vera Tereza. Os sentidos e a experiência: professores, alunos e métodos de ensino. In: SAVIANI, Dermeval et al. O legado educacional do século XX no Brasil. Campinas: Autores Associados, 2006. p. 163-203. 
Notas:

${ }^{1}$ Mestre em Educação pelo Programa de Pós-Graduação em Educação da Universidade Estadual de Maringá (UEM). Professora na Universidade Estadual do Paraná (UEPR) campus de Campo Mourão - FECILCAM.

${ }^{2}$ Doutora em Educação pela Universidade Estadual de Campinas (UNICAMP). Professora na Universidade Estadual de Maringá (UEM).

${ }^{3}$ O documento "Regulamento da Instrução Pública do Estado do Paraná (Decreto n 31 de janeiro de 1890)" encontra-se disponível no acervo do Arquivo Público do Paraná. Agradecemos ao Arquivo a disponibilização do material para estudo e digitalização.

${ }^{4}$ No Paraná, a política imigrantista consistiu na propaganda para atrair novos contingentes populacionais e para a criação da sociedade de migração. Esse ideário fortaleceu-se pelo discurso abolicionista e pela realidade de excedente de mão-de-obra na Europa, resultante da industrialização e mecanização da lavoura. No estado, o processo imigratório se desenvolve em meados do século XIX, mas é, sobretudo, no século XX que se observa o movimento de uma maior quantidade de pessoas, em especial imigrantes do Leste europeu, poloneses e italianos (MAGALHÃES, 2001). Segundo Magalhães (2001, p. 32), "a importância da política da imigração no Paraná é de duas ordens: a primeira, pelo povoamento do território, diversificação das atividades econômicas e decisiva contribuição à urbanização, fatores que cooperam para o crescimento das receitas públicas; a segunda, de se formar no Paraná, como de resto na região Sul como um todo, a primeira classe média do país (composta por pequenos proprietários rurais, artesãos e comerciantes), segmento que, pela sua simples presença, concorre para a democratização da propriedade e do poder."

5 José Marques Guimarães (1838-1903) assumiu o cargo de governador do Paraná no dia 03 de dezembro de 1889. Em 11 de dezembro, dissolveu a Assembleia Legislativa, nomeando uma Comissão Municipal chefiada pelo Dr. Vicente Machado. Ele não exerceu três meses a administração do estado, deixando o governo do Paraná em 18 de fevereiro de 1890. 